\title{
Economia Criativa e Territórios Usados: um debate baseado nas contribuições de Milton Santos
}

LISIANE CLOSS

Universidade Federal do Rio Grande do Sul / Programa de Pós-Graduação em Administração (PPGA/UFRGS),

PORTO ALEGRE - RS, BRASIL

SIDINEI ROCHA-DE-OLIVEIRA

Universidade federal do Rio Grande do Sul / Programa de Pós-Graduação em Administração (PPGA/UFRGS),

PORTO ALEGRE - RS, BRASIL

\section{Resumo}

Este trabalho explora a literatura internacional e nacional sobre espaços criativos, destacando os aportes teóricos de Milton Santos sobre territórios e suas contribuições para o tema. Delimita-se um conceito de território criativo que incorpora uma perspectiva crítico-reflexiva de análise para os estudos nesse campo teórico e favorece uma abordagem de desenvolvimento que contemple aspectos das formações econômicas, sociais e simbólicas de um determinado espaço. Ressalta-se o potencial das discussões realizadas para auxiliar o planejamento de políticas públicas voltadas para o desenvolvimento de territórios criativos que integrem: inclusão social, sustentabilidade, inovação e diversidade cultural.

Palavras-chave: Territórios. Territórios criativos. Milton Santos. Políticas públicas.

\section{Creative Economy and Used Territories: a debate based on the contributions of Milton Santos}

\begin{abstract}
This article explores the international and national literature on creative spaces, highlighting the theoretical inputs of Milton Santos about the concept of territory, as well as other contributions he has bought to the subject. The article establishes a concept of creative territory that incorporates a critical and reflective perspective of analysis for studies in this theoretical field. In addition, it promotes an approach of development that includes aspects of economic, social and symbolic formation in a specific space. The discussions presented in this article have the potential to assist the planning of public policies for the development of creative territories that include social inclusion, sustainability, innovation and cultural diversity.
\end{abstract}

Keywords: Territories. Creative territories. Milton Santos.

\section{Economía Creativa y Territorios Usados: un debate sobre las contribuciones de Milton Santos}

\section{Resumen}

Este trabajo explora la literatura nacional e internacional sobre los espacios creativos, destacando las aportaciones teóricas de Milton Santos a respecto de los territorios y sus contribuciones al tema. Se delimita un concepto de territorio creativo que incorpora una perspectiva de análisis crítico reflexivo para los estudios en este campo teórico y favorece un enfoque de desarrollo que incluya aspectos de las formaciones económicas, sociales y simbólicas de un espacio determinado. Se enfatiza el potencial de las discusiones para ayudar a la planificación de las políticas públicas para el desarrollo de los territorios creativos que integren: inclusión social, sostenibilidad, innovación y diversidad cultural.

Palabras clave: Territorios. Territorios creativos. Milton Santos. Políticas públicas. 


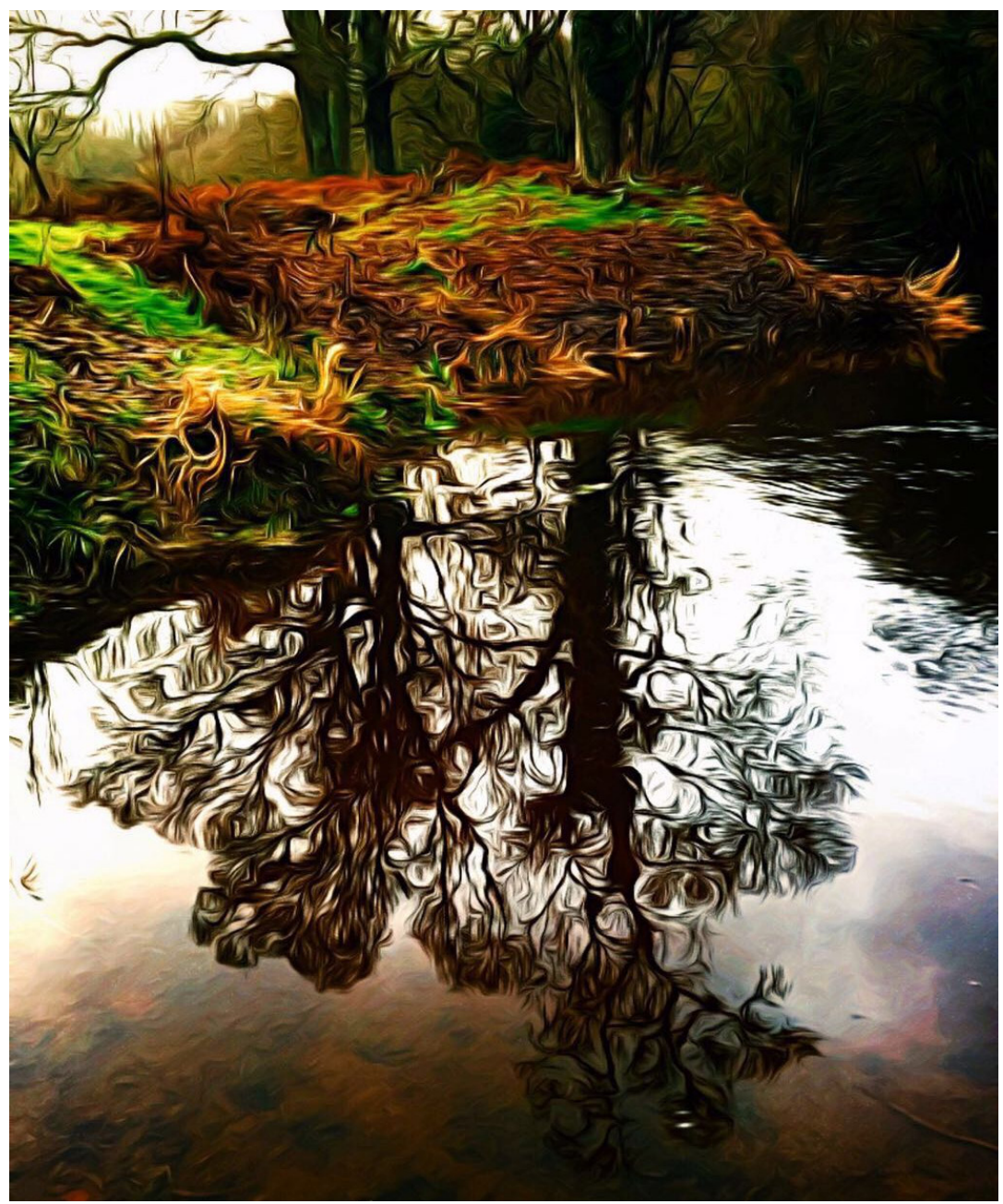

\section{INTRODUÇÃO}

O conceito de Economia Criativa originou-se da designação de indústrias criativas, iniciado em países industrializados a partir dos anos 1990, para caracterizar os setores em que a criatividade é um elemento essencial do negócio (MONTAG, MAERTZ e BAER, 2012). Relacionado ao reposicionamento das indústrias culturais e à sua revitalização no contexto de desenvolvimento urbano da Inglaterra, surge o conceito de cidade criativa (COMUNIAN, 2011). Seu foco, até o final dos anos 1990, estava no aprimoramento de cidades, com ênfase em potenciais retornos econômicos obtidos por meio de atividades e intervenções culturais. A acepção do conceito de "indústrias criativas" implicou uma interpretação da concepção de "cidade criativa" como um local que concentra e apoia indústrias criativas (COMUNIAN, 2011).

Desde então, o termo "criativo", sob o enfoque de espaço geográfico, vem disseminando-se e abarcando diferentes perspectivas teóricas. Na revisão de literatura apresentada sobre o tema neste trabalho, percebe-se uma ausência de precisão em torno desses conceitos, observando-se ambiguidade nas terminologias utilizadas (BORÉN e YOUNG, 2013; COMUNIAN, 2011; REIS, 2011). Cidades criativas, territórios, polos, regiões e ambientes, entre outros termos, aparecem nos estudos sem que haja maior preocupação com uma delimitação desses conceitos. Destaca-se, no entanto, que a terminologia que concentra

* Fonte da imagem: Christophe Peeters (fotógrafo). 
a maior parte dos trabalhos e reúne, em grande parte, muitas das concepções citadas anteriormente, é a de cidades criativas, razão pela qual aparece em destaque neste ensaio teórico.

Considerando que o conceito de Economia Criativa está ligado a elementos locais, o espaço no qual se desenvolvem as ações e empreendimentos torna-se um elemento relevante para ser problematizado e compreendido. No Brasil, Lima (2011) salienta o desafio de promover o desenvolvimento do Brasil diante de sua extensão continental e das diferenças sociais, econômicas, regionais, organizativas e culturais dos seus territórios.

Apesar de o termo território ser frequentemente citado e inserido em muitas das pesquisas que envolvem bairros, polos ou cidades criativas, raramente o seu conceito está definido. Acredita-se, no entanto, que refletir sobre sua concepção possa contribuir de modo significativo para o avanço dos estudos nesse campo teórico e para a formulação de políticas públicas voltadas ao desenvolvimento de territórios criativos.

Dessa forma, acredita-se ser necessário que a discussão sobre Economia Criativa incorpore conceitos que contemplem as configurações sociais locais. Assim, este trabalho apresenta e defende o conceito de território criativo como forma de romper com as limitações dos conceitos já existentes de cidade e polo criativo. Essa ideia baseia-se em Saquet (2011), que sugere a necessidade de uma nova concepção de geografia, de desenvolvimento, de planejamento e de gestão do território para orientar processos participativos e democráticos de gestão e desenvolvimento local.

Para alcançar este objetivo, no presente trabalho efetuou-se o exame da literatura nacional e internacional, tendo se destacado estudos que analisam concepções territorialmente localizadas. Na literatura internacional, foram consideradas as principais discussões sobre o conceito de cidade criativa, tendo sido exploradas suas potencialidades e principais críticas. Na literatura nacional, explorou-se o conceito de polo criativo, apresentando-se as suas principais limitações. A seguir, buscou-se discutir o trabalho de Milton Santos para ampliar perspectivas de análise sobre o tema. Na terceira parte foram feitas articulações entre os aportes teóricos, indicando eixos que podem ser explorados na concepção de territórios criativos. Nas considerações finais foram retomados os aspectos centrais do estudo e destacada uma agenda de pesquisa.

\section{ECONOMIA CRIATIVA: POTENCIALIDADES E LIMITES PARA O DESENVOLVIMENTO}

A Economia Criativa é concebida como o novo modelo de desenvolvimento proposto pela Organização das Nações Unidas (UNCTAD, 2010), compreendendo setores e processos cujo insumo principal é a criatividade para "[...] gerar localmente e distribuir globalmente bens e serviços com valor simbólico e econômico" (REIS, 2008, p. 24, grifo original). A Economia Criativa está também associada aos Objetivos de Desenvolvimento do Milênio (ODM) no que tange à participação de comunidades em formas organizativas e de governança diferenciadas, bem como em produções econômicas de pequeno porte inseridas na dinâmica criativa que fomenta a sustentabilidade e a inclusão econômica e social (LIMA, 2011). Essa concepção vem recebendo atenção crescente no cenário econômico internacional, já que a criatividade contribui para uma perspectiva de desenvolvimento centrado nas pessoas e é insumo essencial para a criação de empregos e para a inovação, favorecendo a inclusão social, a diversidade cultural e a sustentabilidade (UNCTAD, 2010).

A Economia Criativa vem sendo considerada um pilar estratégico de desenvolvimento para os diversos países e continentes no presente século. Como a criatividade é um recurso imaterial existente em todos os países, torna possível promover o desenvolvimento independente do estágio em que estejam suas economias (DE MARCHI, 2014). Desse modo, representa uma alternativa às políticas de desenvolvimento baseadas na industrialização intensiva e na "modernização" de culturas locais, possibilitando aos países em desenvolvimento a produção de bens e serviços com alto valor agregado e, com isso, o benefício de suas culturas locais (artes e folclore, imaginário, conhecimento e modos de vida locais), sem causar danos ao meio ambiente.

No Brasil, as discussões sobre Economia Criativa ainda são incipientes, tendo recebido pouca atenção de pesquisadores. As obras de Bendassoli et al. (2009) e Machado (2009) representam alguns dos primeiros esforços de compreensão neste campo emergente. Estes trabalhos centram-se na análise teórica do conceito, exploram as aproximações e distanciamentos do conceito de indústria cultural (MACHADO, 2009) e efetuam uma análise de outros conceitos semelhantes, tais como indústria criativa, indústria cultural, indústria de conteúdo digital e indústria de conteúdo. Em ambos os trabalhos, destaca-se a possível emergência de um novo significado para um conjunto de atividades ligado à cultura, com uma valorização mais 
econômica e afastada da vertente crítica apresentada pela indústria cultural. Ressalta-se que a discussão sobre o território está ausente nos artigos nacionais.

No plano empírico, notam-se ações do governo que indicam reconhecimento e incentivo a políticas segundo os preceitos desenvolvidos em cenário internacional. O Ministério da Cultura criou a Secretaria da Economia Criativa, estabelecendo como desafio liderar a formulação, implementação e monitoramento de políticas públicas voltadas para um desenvolvimento alicerçado na inclusão social, na sustentabilidade, na inovação e na diversidade cultural brasileira (MINC, 2011). Assim, conforme De Marchi (2014), este ministério assumiu-se como proponente de uma política socioeconômica transversal, baseada no trabalho imaterial, por meio de uma coordenação estratégica com outras secretarias e ministérios, colocando-se no centro dessa rede para o desenvolvimento de uma macropolítica para o desenvolvimento nacional.

Segundo Martins, Vaz e Caldas (2010), a formulação de políticas públicas requer a contextualização do local, o que significa relacioná-lo com as instâncias regional, nacional e internacional. Para compreender as articulações complexas envolvidas nesse processo, os autores sugerem a articulação simultânea entre instrumentos e atores em estratégias situacionais de desenvolvimento local singulares no tempo e no espaço, destacando o caráter multidimensional e multiescalar desses processos. A busca de soluções para questões relativas ao desenvolvimento de territórios, segundo os autores, exige o descarte de modelos preconcebidos ou de best practices e a observação de uma diversidade de experiências de desenvolvimento local, identificando questões que surgem do seu conjunto e orientem a uma reflexão que possa subsidiar tanto atores da sociedade civil como dos governos, sobretudo formuladores de políticas públicas.

Para contemplar esses aspectos, a delimitação de espaços geográficos se faz necessária. Por esse motivo, serão abordadas na seção seguinte, como uma dessas delimitações, as cidades criativas.

\section{COMPREENSÕES DO ESPAÇO NA ECONOMIA CRIATIVA: CIDADES E POLOS}

De acordo com Comunian (2011), o conceito inicial de cidade criativa foi formulado por Bianchini e Landry (1995) e estava relacionado ao reposicionamento das indústrias culturais e à sua revitalização no contexto de desenvolvimento urbano da Inglaterra, entre o fim dos anos 1980 e o início dos anos 1990. Seu foco, até o final dos anos 1990, estava no aprimoramento da cidade, com ênfase em potenciais retornos econômicos obtidos por meio de atividades e intervenções culturais.

A acepção do conceito de indústrias criativas implicou uma interpretação da cidade criativa como um local que concentra e apoia indústrias criativas (COMUNIAN, 2011). Teorias mais recentes sobre o tema, tais como a de Florida (2003), destacam o papel da criatividade na geração de inovação e crescimento regional. Sob essa visão, pessoas criativas - ou a classe criativa, cujos integrantes se "[...] engajam em trabalhos cuja função é a de criar novas formas significativas" (FLORIDA, 2003, p. 8) - são o "motor" que impulsiona o crescimento econômico. A cidade criativa, segundo essa concepção, pode ser entendida como uma cidade com elevada presença ou capacidade de atrair a classe criativa. Desse modo, Florida (2003) sugere que cidades e regiões deveriam promover a cultura, a diversidade cultural e o entretenimento, e destaca, nesse caso, a necessidade de três fatores críticos: tecnologia, talento e tolerância.

Landry (2011), outro autor seminal nos estudos sobre cidades criativas, apresenta dez indicadores para avaliar um local criativo, quais sejam: 1) contexto político e público; 2) distinção, diversidade, vitalidade e expressão; 3) abertura, confiança, tolerância e acessibilidade; 4) empreendedorismo, exploração e inovação; 5) liderança estratégica, agilidade e visão; 6) talento e perspectiva de aprendizagem; 7) comunicação, conectividade e redes; 8) o lugar e o placemaking (relacionado a planejamento, desenho e gestão do espaço público); 9) habitabilidade e bem-estar; 10) profissionalismo e efetividade. $O$ autor sugere ainda a busca das seguintes qualidades: motivação, tenacidade, consciência, comunicação clara, pensamento aberto, inspiração, aspiração, adaptabilidade, dinamismo, abertura, participação, sensibilidade para o design, apreço sensorial, orguIho profissional, liderança e visão.

Em revisão de literatura internacional realizada sobre elementos que parecem favorecer o desenvolvimento de indústrias culturais ou criativas e, simultaneamente, o posicionamento de cidades e territórios como criativos, Pareja-Eastway (2010) identificou as seguintes características: qualidades pessoais, vontade e liderança, diversidade humana e acesso a talento variado, cultura organizativa, identidade local, espaços urbanos e equipamentos, bem como dinâmicas de redes. A autora salienta 
ainda que os fatores soft, tais como qualidade residencial, ambiente e tolerância; além dos fatores relacionados a network, tais como haver nascido no local, contatos sociais e profissionais, são mais relevantes para a economia criativa em determinado local. Ademais, a contextualização de uma determinada cidade em sua própria trajetória histórica, contemplando aspectos econômicos, culturais e políticos, contribui decisivamente para a singularidade das cidades que hoje se denominam "criativas" (PAREJA-EASTWAY, 2010).

Os estudos citados anteriormente exemplificam o enfoque das pesquisas sobre cidades e regiões criativas, predominante em anos recentes, como modelos de desenvolvimento urbano e prosperidade. O foco desses trabalhos é voltado para o que uma cidade deve fazer ou ter para ser ou se tornar "criativa" (COMUNIAN, 2011; FLORIDA, 2002; JAKOB, 2010; YDE, 2012), subsidiando a formulação de políticas públicas e gerando guias de soluções para o desenvolvimento da economia local e a solução de problemas urbanos (COMUNIAN, 2011; BORÉN e YOUNG, 2013; EVANS, 2009; SCOTT e STORPER, 2009).

Essas teorias, no entanto, vêm sendo criticadas de diferentes perspectivas. Borén e Young (2013) apontam que as políticas públicas se vinculam a imperativos econômicos e a uma agenda neoliberal. Assim, ignoram os efeitos redistributivos potencialmente negativos, tais como investimentos em recursos culturais de grande porte - a exemplo de casas de espetáculos ou estádios esportivos - para tornar a cidade "atrativa". Essas ações podem promover formas estereotipadas de atividades criativas voltadas para o crescimento urbano, em detrimento de investimentos em bem estar social, educação, saúde ou apoio a outras formas de criatividade (BORÉN e YOUNG, 2013).

Além disso, a literatura existente sobre cidades criativas retrata especialmente experiências dos Estados Unidos, da Europa e Australásia (CHOI, MILAR e WONG, 2006; COMUNIAN, 2011; CURRID, 2006; JAKOB, 2010), o que resulta em pouco conhecimento a respeito do tema em outros contextos. Diferentes tipos de cidades e áreas urbanas envolvem distintas legislações, contextos políticos, hierarquias urbanas, estruturas de governança, geografias urbanas internas e tradições culturais (BORÉN e YOUNG, 2013), requerendo, portanto, diferentes compreensões do espaço criativo, já que as atividades e dinâmicas criativas são situadas, estando diretamente relacionadas a um ambiente específico (COHENDET, GRANDADAM e SIMON, 2009).

Frequentemente, com o foco em uma audiência internacional, algumas formas de criatividade tornam-se valorizadas pelas elites urbanas e gozam de financiamentos públicos. No entanto, outras - possivelmente mais mundanas, suburbanas ou experimentais - são ignoradas, suprimidas, desvalorizadas ou excluídas das políticas públicas voltadas para o desenvolvimento das cidades criativas, causando a supressão da criatividade que supostamente deveria envolver tais atividades (BORÉN e YOUNG, 2013).

De acordo com Yde (2012), Florida se propõe a identificar e entender as relações causais entre personalidade, inovação, capital humano, classe criativa, renda e crescimento econômico. Para a autora, isso demonstra que a personalidade, até então limitada ao âmbito privado, passa a ser parte essencial do econômico, da produção e mesmo da configuração da cidade Florida afirma que as cidades possuem personalidades específicas. Assim, a personalidade dos cidadãos passa a não ser indiferente à economia; interessa, portanto, que os sujeitos sejam empreendedores, inovadores, criativos, já que nesses perfis pessoais está o cerne do potencial produtivo e econômico da cidade (YDE, 2012).

Comunian (2011, p. 1159) assinala outra crítica a Florida: a de assegurar a si mesmo contratos de consultorias para desenvolver "políticas urbanas rápidas" direcionadas a cidades criativas. Políticas como as propostas por Florida e outros autores, segundo Borén e Young (2013), vêm sendo amplamente adotadas, pois, aparentemente, são baseadas em análises estatísticas e oferecem soluções, relativamente fáceis de implementar, para problemas econômicos. Os autores observam, no entanto, que tais soluções se disseminaram rapidamente não por sua eficácia, mas por se adequarem facilmente às políticas (culturais e de urbanismo) existentes, sem a exigência de mudanças profundas por parte de seus formuladores ou mudanças nos interesses e estruturas de poder, condizente com as perspectivas do urbanismo neoliberal e do cosmopolitismo competitivo.

Conforme Jakob (2010), esses modelos apenas repaginam um modelo empreendedor de governança urbana e desenvolvimento voltado para atrair capitais altamente voláteis e elites profissionais. Entretanto, não desconsidera a relevância de toda a concepção de Cidades Criativas e a possibilidade de um desenvolvimento urbano valendo-se das artes. O que a autora propõe é a necessidade de uma revisão profunda do modelo de Cidade Criativa dominante, tendo em vista o prevalecimento da igualdade e da participação cívica em vez do crescimento. Desse modo, a criatividade pode ser apropriada como um direito humano e não como uma estratégia de desenvolvimento urbano. 
Borén e Young (2013) defendem que é preciso ir além da dicotomia entre os trabalhos que celebram a criatividade e os que rejeitam um papel para a criatividade na cidade, abrindo novos caminhos para estudos acadêmicos interdisciplinares que auxiliem formuladores de políticas públicas e atores envolvidos em atividades criativas a interagir de um modo mais produtivo.

Além disso, Borén e Young (2013) destacam que a definição de criatividade pode variar tanto em sua forma quanto em seus objetivos nas esferas de políticas municipais e nas diferentes formas de governança urbana em escala submunicipal. Essas escalas podem não se alinhar com políticas voltadas ao incremento de equipamentos culturais para aumentar sua atratividade e, sim, em vez disso, utilizar a cultura e a criatividade nas áreas da educação, sustentabilidade, igualdade e coesão social, desenvolvimento pessoal, como "arte pela arte", ou se ater mais em exercer pressão sobre questões socioeconômicas (BORÉN e YOUNG, 2013).

Yde (2012) argumenta que as configurações urbanas precisam afastar-se de entendimentos como delimitações geográficas ou como conglomerados de habitantes e edifícios. Elas devem ser exploradas como formas de vida, espacialidades e redes semióticas que se comunicam e se modificam constantemente, o urbano entendido como uma "[...] forma de fazer, organizar, sentir, funcionar, administrar, conceber, nomear, habitar e relacionar-se" (YDE, 2012, p. 170). Segundo a autora, é necessário conceber a cidade criativa como uma produção de redes sociomateriais específicas em constante atualização, e não como um modelo abstrato ou unidade estável, passível de ser analisada como unidade econômico-espacial delimitada. Para tanto, sugere a necessidade de estudos de casos específicos que abordem de forma empírica os processos de composição e emergência desse diagrama de cidade.

No contexto brasileiro, embora surjam trabalhos voltados à compreensão da economia criativa (BENDASOLLI et al., 2009; MACHADO, 2009) e análise das políticas governamentais (DE MARCHI, 2014), são raros aqueles que consideram o território na discussão sobre o tema. A compreensão deste é de fundamental importância para executar ações que promovam o seu desenvolvimento em face de sua extensão continental e das diferenças sociais, econômicas, regionais, organizativas e culturais dos seus territórios (LIMA, 2011).

Como forma de compreensão do espaço, destaca-se no cenário nacional o trabalho de Lima (2011), que ressalta a necessidade de apresentar novas soluções, propostas e rumos que contribuam para o desenvolvimento de polos criativos, concebidos como conjuntos de empreendimentos criativos situados geograficamente próximos e restritos a um território de pequena dimensão. Polos criativos, de acordo com a autora, constituem-se espaços de convivência urbana que possuem uma dinamização funcional, reunindo em sua geografia distintos grupos e pessoas com uma identidade cultural singular, com a realização de variadas atividades associadas a dimensões simbólicas (LIMA, 2011).

Sob esse enfoque, existem poucos referenciais retratando experiências sobre bairros criativos, conceito similar ao de polos. Um dos exemplos citados pela autora, nesse sentido, é o bairro Vila Madalena, em São Paulo, que reúne atividades cívicas, culturais, institucionais e comerciais, proporcionando pontos de encontros formais e informais. Diferenciando-se dos bairros criativos, os polos criativos excluem o critério da delimitação territorial regional. Assim, os polos criativos apresentam características específicas de dinamismo da Economia Criativa em um dado espaço geográfico, as quais constituem a identidade do polo e a base de aglomeração dos seus atores.

O potencial de dinamização da economia e a atratividade turística desses territórios se destacam e propiciam experimentações e trocas entre cidadãos e visitantes, gerando oportunidades de desenvolvimento local. Pardo (2011) alerta, no entanto, que é preciso cuidar para não transformar tais territórios em locais unicamente turísticos, sob o risco de eliminar a complexa diversidade do tecido urbano, o que pode gerar perda da qualidade de vida dos cidadãos, bem como da personalidade e atratividade para o desenvolvimento das suas atividades criativas.

Nove critérios inter-relacionados são destacados como indispensáveis na qualidade de identificadores de um polo criativo e agrupados em três campos de atuação: a) campo da economia e da gestão; b) campo da identidade e da cultura; e c) campo das relações sociais (LIMA, 2011). Fazem parte do campo da economia e da gestão: o desenvolvimento da atividade econômica local; convergências de atuação (sinergia em busca de objetivos comuns relativos ao desenvolvimento sustentável local); concentração setorial de iniciativas (vocação setorial para as atividades produtivas se relacionarem e, então, se constituírem em um polo criativo) e o adensamento empresarial para desenvolvimento pessoal autônomo; incremento da implantação de pequenos negócios; crescimento da oferta de postos de trabalho e do volume de produtos/serviços gerados e comercializados. 
No campo da identidade e da cultura, Lima (2011) propõe como itens: a construção da imagem coletiva (relacionada ao ambiente arquitetônico, aos elementos históricos e culturais locais) e o valor agregado intangível (aspectos que tornam produtos e serviços exclusivos, distinguindo-se de mercadorias produzidas em grande escala). No campo das relações sociais destacam-se: formas de governança próprias (instâncias e instrumentos de participação cidadã com capacidade de ação não apenas entre si, mas com os poderes públicos e outras instâncias do poder ou econômicas); desenvolvimento de tecnologias ligadas à Economia Criativa para ampliar a relação entre capital e criatividade humana, sendo um fator predominante na Economia Criativa a sustentabilidade ambiental e social.

Assim, ligados aos preceitos da Economia Criativa, cidades e polos criativos são conceitos apresentados para compreensão dos espaços. No primeiro, a delimitação do espaço segue uma orientação da geografia tradicional, guiando-se pela demarcação formal da cidade e pela busca do retorno financeiro decorrente da sua utilização. No segundo, cujo foco são os polos criativos, apesar de menos explorado, há uma preocupação em considerar os aspectos humanos que marcam o território, bem como a relevância das formas de governança e interação dos atores que participam do território.

Nota-se, como posicionamento teórico epistemológico predominante nestas análises, bem como em quase toda a discussão atual sobre Economia Criativa, o funcionalismo-estrutural, baseado nos imperativos da emergência de um modelo global de organização dos espaços e na definição de normas e papéis a serem seguidos e evitados pelos atores que ocupam estes espaços. Quando se assumem os preceitos da economia liberal, o objetivo central é tornar os bairros e/ou cidades atrativos para ampliar os ganhos financeiros do local (BORÉN e YOUNG, 2013; JAKOB, 2010); em segundo plano (quando considerados) ficam o contexto sócio-histórico e as diferentes relações sociais dos ocupantes destes espaços.

Embora Lima (2011) destaque que as dimensões que constituem um território envolvam os campos socioeconômico, físico-territorial, político-organizativo e simbólico-cultural, sua proposta mantém uma matriz economicista, que pode ser notada no enfoque dado à produção e ao consumo nos itens que aborda. Mesmo a dimensão cultural e simbólica apresentada pela autora traz em seu interior uma valorização econômica: trata-se de um meio de atrair possíveis consumidores.

Como forma de ampliar a discussão sobre Economia Criativa, sobretudo no que se refere ao espaço, a próxima seção apresenta conceitos e pressupostos de Milton Santos para compreensão sócio-histórica do território. Acredita-se que os conceitos de espaço e território propostos por Milton Santos possam contribuir para os debates nesse campo teórico, tema explorado a seguir.

\section{TERRITÓRIOS: O ENFOQUE DE MILTON SANTOS}

Nesta seção buscamos explorar as contribuições do geógrafo Milton Santos à discussão sobre o espaço relacionado com a temática da Economia Criativa. Apesar de ser reconhecido como um dos principais expoentes na geografia brasileira, com elaborações teórico-metodológicas reproduzidas nacional e internacionalmente, seu trabalho ainda é pouco estudado e utilizado no Brasil, possivelmente devido a uma prática acadêmica que valoriza pesquisadores estrangeiros em detrimento dos nacionais (SAQUET e SILVA, 2008).

Milton Santos foi pioneiro e renovador das compreensões do espaço na geografia, propondo um método de interpretação pautado no materialismo histórico. Sob essa concepção, a produção do conhecimento é gerada, inicialmente, pela realidade material, pois o real possui o movimento e é nele que se encontram as relações, sendo necessário um pensamento dialético para a sua compreensão (FARIA, 2011). De acordo com Faria (2011, p. 6), existem cinco características que distinguem o materialismo histórico de outros tipos de materialismo:

(i) O mundo é material e os múltiplos fenômenos, que se relacionam e se condicionam reciprocamente, são diferentes aspectos da matéria em movimento; (ii) A matéria (realidade objetiva) é anterior à consciência, pois é a fonte das representações; (iii) O mundo é cognoscível, sendo a práxis (teoria e a prática) relevante para a consciência: não há diferença entre a propriedade de uma coisa e a própria coisa; (iv) O conhecimento não é uma operação pela qual o pensamento interpreta os dados dos sentidos, mas um processo complexo de interação entre o sujeito e o objeto; (iv) As leis da natureza e da sociedade são históricas, sendo a história uma construção humana marcada pelos modos de produção. 
Nessa perspectiva, a história torna-se central, como ciência que integra em um processo único a evolução da natureza, da sociedade e do pensamento, buscando compreender as leis gerais e as particulares desse processo, específicas de determinados períodos. A essência do método dialético encontra-se na unidade indestrutível em que se constituem o absoluto e o relativo: a verdade absoluta possui elementos relativos, associados ao tempo, às circunstâncias e ao lugar; já a verdade relativa, como reflexo aproximadamente fiel da realidade, encobre-se de uma validez absoluta (LUKÁCS, 2010).

Conforme Lukács (2010), por intermédio do trabalho os indivíduos criam a si mesmos. Essa função criadora é determinada por circunstâncias objetivas, sociais ou naturais, assim como suas possibilidades e graus de desenvolvimento. Na concepção da estética marxista, por exemplo, não é possível desvincular a unidade entre o processo histórico e o valor estético permanente de uma obra de arte (LUKÁCS, 2010).

Seguindo este caminho de análise na Geografia, Santos (2005a) destaca que a relação espaço-tempo representa o elemento central da dinâmica socioespacial da geografia humana. Nesse caso, compreende-se o espaço como produção do homem na relação com a totalidade da natureza e por meio da técnica. As formações ideológicas são características de um determinado tempo e se explicam pela práxis material, que é socialmente determinada e se constitui como um todo orgânico, dinâmico, marcada por relações distintas que se conectam em diferentes momentos (CHAGAS, 2011).

Milton Santos teve participação marcante na renovação da geografia nacional entre os anos de 1960-1980, baseando sua elaboração na relação dialética para compreensão de tempo-espaço (SAQUET e SILVA, 2008). Para Santos (2005c), o homem transforma a natureza segundo as leis situadas historicamente em determinado espaço. Logo, a ideia de espaço torna-se fundamental para compreender a produção do homem em sua relação com a natureza e com a técnica. Para Santos (2005c, p. 28):

Os modos de produção tornam-se concretos sobre uma base territorial historicamente determinada. Desse ponto de vista, as formas espaciais seriam uma linguagem dos modos de produção. Daí na sua determinação geográfica, serem eles seletivos, reforçando desta maneira a especificidade dos lugares.

A localização dos homens, das atividades e das coisas no espaço explica-se tanto pelas necessidades "externas", aquelas do modo de produção "puro", quanto pelas necessidades "internas" representadas essencialmente pela estrutura de todas as procuras e estrutura das classes, isto é, a formação social propriamente dita.

Assim, Santos (2005c) integra e reforça a importância da discussão sobre espaço na formação das relações de produção. Salienta que modo de produção, formação social e espaço são categorias interdependentes e estabelecidas histórica e espacialmente como formação social. Para Santos (2005a), o espaço é uma categoria pouco explorada mesmo na Geografia, na qual predomina uma análise da forma em detrimento da formação. Um olhar que se concentra nas formas cristalizadas, impedindo que se faça uma relação maior entre espaço e História, explorando as relações sociais, políticas e econômicas do processo de formação. Desse modo, o autor destaca:

O espaço é a matéria trabalhada por excelência. Nenhum dos objetos sociais tem tamanha imposição sobre o homem, nenhum está tão presente no cotidiano dos indivíduos. A casa, o local de trabalho, os pontos de encontro, os caminhos que unem estes pontos são igualmente elementos passivos que condicionam as atividades do homem e comandam a prática social. (SANTOS, 2005a, p. 34).

Baseando-se na importância da compreensão do espaço como base para as relações sociais, o autor situa seus estudos numa crítica frequente à consideração do espaço apenas relacionado à delimitação geográfica. Para o autor, o espaço, mais do que delimitações cartográficas, é um espaço ocupado, que precisa ser compreendido em associação àqueles que o habitam. A localização dos homens e das atividades e das coisas precisa ser compreendida mediante as formas de produção e dos elementos internos do espaço, como a organização social e material (SANTOS, 2002). Segundo Marx e Engels, há um entrelaçamento entre a produção de ideais e representações realizadas pelos indivíduos e as circunstâncias reais, condições materiais e meios para satisfazer necessidades vitais, que nascem da "[...] produção e o intercâmbio material da vida social-humana" (CHAGAS, 2011, p. 62). 
Assim, Santos (2005a) propõe como categoria de análise a formação econômica e social (FES), que diz respeito "[...] à evolução diferencial das sociedades, no seu quadro próprio e em relação com as forças externas de onde mais frequentemente lhes provêm o impulso" (p. 22). A FES expressa a relação entre as esferas econômica, política, social e cultural de uma sociedade, num movimento dinâmico entre unidade e totalidade geográficas e as continuidades e descontinuidades do seu tempo histórico.

O estudo das formações econômicas e sociais possibilita aprofundar a compreensão sobre a totalidade e as frações que integram uma sociedade. Cada formação possui especificidades que a distinguem de outras; em seu interior existem separações, frações do todo. A totalidade apresenta elementos variáveis que interagem e se modificam ao longo do tempo. A análise deste movimento requer a articulação dos conceitos de modo de produção, formação social e espaço que se influenciam mutuamente. O modo de produção se expressa nas formas de produção, circulação e distribuição histórica e espacialmente determinadas em um movimento conjunto (SANTOS, 2005a). A formação social é uma estrutura técnico-produtiva expressa geograficamente por certa distribuição da atividade de produção, não pode, dessa forma, ser dissociada do espaço em que ocorre.

Na relação de interdependência estabelecida entre os três conceitos, o autor afirma que a formação social possui uma história constituída pela sequência de formas que surgem em um território espacial, na relação com as mudanças dos modos de produção. Essa relação é apresentada pelo autor no seguinte trecho:

A realização prática de um dos momentos da produção supõe um local próprio, diferente para cada processo ou fração do processo, o local torna-se assim, a cada momento histórico, dotado de uma significação particular. A localização num dado sítio e num dado momento das frações da totalidade social depende tanto das necessidades concretas de realização da formação social quanto das características próprias do sítio. $O$ uso produtivo de um segmento de espaço num momento é, em grande parte, função das condições existentes no momento inicial. (SANTOS, 2005a, p. 30-31).

Em cada momento histórico, a forma espacial é reconfigurada, tanto pelas heranças presentes no espaço organizado, quanto pelas necessidades do espaço presente, representado pela ação do modo de produção ou de um dos seus momentos (SANTOS, 2005a). Williams (2011) sugere refletir como se houvesse uma relação temporal entre uma cultura dominante, uma residual e outra emergente, em que novas práticas, significações e experiências são constantemente criadas.

Essas reconfigurações espaciais são marcadas por continuidades e descontinuidades. Segundo o autor:

A unidade da continuidade e descontinuidade do processo histórico não pode ser realizada senão no espaço e pelo espaço. A evolução da formação social está condicionada pela organização do espaço, isto é, pelos dados que dependem diretamente da formação social atual, mas também das FES permanentes. (SANTOS, 2005a, p. 32).

Além disso, o espaço é tanto efeito quanto condição da transformação de uma sociedade global. A continuidade e descontinuidade se apresentam, além da articulação entre herança e presente, também na relação entre o global e o local (totalidade e lugar). As formações sociais do lugar são pressionadas para seguir a totalidade, mas a resposta apresentada é marcada por elementos de ligação e afastamento em virtude das características históricas que o marcam. No entanto, ao longo do tempo, as formas socioespaciais podem ser renovadas, adaptadas; ou, ainda, novas podem ser criadas pela apresentação de um novo modo de produção, uma totalidade que busca integração.

Dessa perspectiva, Milton Santos (2002) chega à discussão sobre território, que, em uma definição ampla:

[..] não é apenas um conjunto de sistemas naturais e de sistemas de coisas sobrepostas, o território pode ser entendido como território usado, não o território em si. O território usado é o chão mais a identidade. A identidade é o sentimento de pertencer aquilo que nos pertence. $O$ território é o fundamento do trabalho; o lugar da residência, das trocas materiais e espirituais e do exercício da vida. (SANTOS, 2002, p. 15). 
Dessa ideia podemos compreender que o território é formado por relações que integram a história, natureza, economia, política e cultura de um determinado espaço. Este último não é apenas o resultado da atuação de uma diversidade de elementos, trata-se de uma estrutura da sociedade que interfere nas demais estruturas (SANTOS, 2002). Um espaço interage com outros espaços, como a totalidade de um Estado ou de um modo de produção. No entanto, esta totalidade poderá apresentar formas diferentes dependendo do lugar, bem como se alterar ao longo do tempo, pois o espaço é uma estrutura ativa.

Ao explorar a noção de território no período de globalização, Santos (2005b) inclui novas categorias e destaca:

[...] o território são formas, mas o território usado são os objetos e as ações, sinônimo de espaço humano, espaço habitado. Mesmo a análise da fluidez posta ao serviço da competitividade, que hoje rege as relações econômicas, passa por aí. De um lado temos a fluidez virtual, oferecida por objetos para facilitar essa fluidez e que são, cada vez mais, objetos técnicos. Mas os objetos não nos dão senão uma fluidez virtual, porque a real vem de ações humanas, que são cada vez mais ações informadas, não normatizadas. (2005b, p. 138).

Nesse contexto contemporâneo, território recebe novos recortes denominados verticalidades e horizontalidades (SANTOS, 2005b). As verticalidades são um conjunto de pontos distantes uns dos outros, ligados por todas as formas de processos sociais, formando um espaço de fluxos. A esses pontos está ligada a utilidade produtiva e uma lógica de individualidade. As verticalidades são "[...] pontos no espaço que, separados uns dos outros, asseguram o funcionamento global da sociedade e da economia" (SANTOS, 2006, p. 284). Elas criam interdependência hierárquica entre lugares, sendo esta proporcional à necessidade de cooperação entre os lugares. Essa hierarquização é importante para a existência e permanência de uma organização espacial que leva ao crescente processo de homogeneização dos lugares. Aqui se estabelece uma relação entre a totalidade e o lugar: a totalidade é uma lógica externa de acordo com a qual os espaços locais são levados a adaptar sua organização e atuação com base nos interesses globais, que mudam constantemente, gerando descontinuidades. Como reação a essa homogeneização, há o processo de desintegração das solidariedades locais, gerando perda na capacidade de gestão da vida local (SANTOS, 2005b).

As verticalidades decorrem da transformação das atividades econômicas no atual processo de desenvolvimento tecnológico e na internacionalização de mercados. Nesse contexto, a coesão entre organizações mundiais passa a influenciar todos os espaços do globo, baseada numa racionalidade de ampliação de ganhos e formação de novas ideias globais. Dessa forma, criam interdependências entre lugares dispersos pelo planeta, integrando-os como redes globais. Essa relação é estratificada e segue uma ordem técnica, financeira e política definida por organizações e países que influenciam a atual ordem geopolítica. Cria-se, assim, uma integração limitada, baseada na alienação e, por vezes, exploração de comunidades locais na formação do sistema econômico mundial. As verticalidades "[...] são vetores de uma racionalidade superior e do discurso pragmático dos setores hegemônicos, criando um cotidiano obediente e disciplinado" (SANTOS, 2006, p. 286).

As horizontalidades são "[...] os domínios de contiguidade, daqueles lugares vizinhos reunidos por uma contiguidade territorial” (SANTOS, 2005b, p. 139). Esses domínios contíguos se opõem ao espaço econômico, constituindo um espaço de todos: empresas, instituições, pessoas - o espaço das vivências. A horizontalidade significa tanto as articulações quanto os benefícios gerados no âmbito local pelas ações de um determinado ator sobre o território onde se instala. Nesses espaços territoriais pode se constituir uma solidariedade formada pelo conjunto de agentes que ali atuam. Eventualmente, o conjunto se transforma, embora essa mudança seja marcada pela continuidade. Verticalidades e horizontalidades são cortes simultâneos e complementares do espaço geográfico. São as fragmentações do espaço, suas funcionalidades e reordenações dos lugares em continuidades geográficas ou não.

Com esses conceitos, Santos (2005) integra as dimensões global e local na compreensão do espaço. A região - o espaço local - é importante para o capital global, sendo a forma como a dimensão da economia internacional se instala e envolve espaços locais com maior possibilidade de maximização dos retornos econômicos. Para compreender como estas relações se estabelecem, o autor defende uma abordagem materialista histórica. Desta forma é possível entender as transformações das relações de produção e como se modifica a articulação entre local e global, bem como entre relações de trabalho e métodos produtivos ao longo do tempo.

Na próxima seção, investiga-se como as bases epistemológicas e os conceitos trabalhados por Milton Santos podem contribuir para ampliar a discussão sobre Economia Criativa e os espaços onde se desenvolve no contexto nacional e internacional. 


\section{ECONOMIA CRIATIVA E TERRITÓRIOS USADOS: DIÁLOGOS COM MILTON SANTOS}

Partindo da base teórica e epistemológica de Milton Santos, isto é, reconhecendo que o homem depende das condições materiais de produção e que estas estão histórica e espacialmente estabelecidas, volta-se, aqui, a analisar a Economia Criativa e as formas como o espaço tem sido discutido nessa perspectiva. Assim, esta análise baseia-se em quatro pontos centrais: a) crescimento e disseminação acrítica da Economia Criativa; b) ausência do contexto sócio-histórico como base para reflexão; c) incorporação da ideia de território usado para compreender o espaço na Economia Criativa.

\section{a) Crescimento e disseminação acrítica da Economia Criativa}

Os estudos sobre Economia Criativa têm se desenvolvido assumindo a globalização como uma verdade única e valorizando uma perspectiva elitista da criatividade (BORÉN e YOUNG, 2013; YDE, 2012). O crescimento de estudos na América do Norte e Europa acabou por direcionar e definir algumas compreensões que não contemplam outros continentes e culturas. Dessa forma, desenvolve-se uma teoria em que predomina a visão de cultura e criatividade desses países em detrimento de outros entendimentos existentes no mundo. Nesse sentido, como destaca Santos (2005), a força totalizante global pressiona os espaços locais para reproduzirem a ordem internacional, gerando pressões transformações nas formações econômicas e sociais.

Além disso, como ressaltam Machado (2009) e Bendassoli et al. (2009), o conceito de Economia Criativa é uma ressignificação de indústria cultural, eliminando a reflexão e a crítica existentes em torno deste conceito e focando nos resultados econômicos decorrentes do trabalho no setor. Para Machado (2009, p. 90), o “[...] processo de globalização coloca na agenda de debates uma série de questões que giram em torno da construção de identidades - nacionais ou culturais e, ainda, individuais - que se associa à questão da diversidade cultural". O conceito de Economia Criativa faria parte dessa nova matriz conceitual, levando a um caminho diferente para compreensão dos fenômenos sociais, afastando-se da vertente frankfurtiana, que seguia como base para compreensão da indústria cultural.

Aqui cabe questionar os limites da compreensão dos fenômenos sociais seguindo os preceitos da Economia Criativa, uma vez que esta busca criar uma ligação permanente entre bens culturais e resultado econômico. Ao destacar o econômico, deixa de considerar aspectos centrais da história, da formação social e das relações de produção em cada país ou região, bem como a nova divisão internacional do trabalho, algo que parece central à compreensão das agendas de políticas públicas elaboradas por organizações nacionais e internacionais para a nova economia da criatividade e da cultura.

Assim, é importante que estudos sobre Economia Criativa reconheçam que esta se insere no movimento de construção de uma matriz conceitual que busca dialogar globalmente. É necessário, portanto, explorar alternativas para a compreensão dos temas ligados às atividades artísticas, à inovação e às produções culturais - típicas da Economia Criativa - que contemplem as relações de produção nelas constituídas, suas transformações históricas e as contradições que marcaram as transformações de cada região ao longo do tempo, o que requer um pensamento dialético (FARIA, 2011).

O foco centrado nos aspectos de desenvolvimento econômico, que desconsidera e desestimula práticas criativas com menor potencial econômico ou as diferenças regionais (YDE, 2012), reforça a ideia totalizante das abordagens de espaço presentes nos estudos sobre Economia Criativa. Essa compreensão contribui para uma reorganização do espaço baseada no interesse econômico, criando uma única forma de compreensão dos objetos de estudo, em que não se consideram as diferenças e as contradições que construíram e foram construídas em um território ao longo do tempo. A adoção e exploração das horizontalidades e verticalidades, com atenção para os aspectos locais, permite ver as redes que se formam e as contradições que este processo pode gerar pela incorporação de novas relações de produção, bem como as disputas que podem surgir na mudança de uma perspectiva de classe regional para uma internacional.

\section{b) A ausência do contexto sócio-histórico como base para reflexão}

Ao seguir uma matriz totalizante, os estudos sobre Economia Criativa desconsideram a história, uma vez que o principal interesse está na reprodução de um modelo único "de sucesso" para bairros e cidades criativos. No entanto, os modos de 
produção das atividades criativas não podem ser dissociados do espaço-tempo em que ocorrem, integrando artes, folclore, imaginário, conhecimento e modos de vida locais - elementos inscritos nas formas de produção, circulação e distribuição (SANTOS, 2005a) de bens e serviços de valor simbólico gerados em um determinado território.

Nos estudos internacionais sobre economia criativa, o espaço é apresentado apenas como forma na delimitação geográfica das cidades, ou seja, o espaço construído e as formas estabelecidas (BORÉN e YOUNG, 2013; YDE, 2012). Essa concepção desconsidera, frequentemente, a história e as relações sociais, econômicas e políticas do processo de formação daquele espaço, bem como a relação e o condicionamento recíprocos entre os múltiplos fenômenos do mundo material, que representam diferentes facetas da matéria em movimento (FARIA, 2011).

Seguindo o raciocínio de Lukács (2010), ao se tomar a história como base para compreensão do território, é possível explorar a totalidade, compreendendo a sociedade, ideias e natureza, as particularidades e contradições, a forma como se estabeleceram as relações de produção de determinado território. Considerando-se uma perspectiva em que se valorizem as formações sociais, o espaço da cidade pode ser reinterpretado, pois os territórios dependem da forma como o espaço é utilizado, das relações de poder estabelecidas e da dinâmica das interações com outros espaços. Desse modo, dentro de uma mesma cidade pode haver diferentes territórios, assim como um território pode integrar diferentes cidades pela história de suas formações econômica e social.

\section{c) A incorporação da ideia de território usado para compreender o espaço na Economia Criativa}

Em um tema de discussão nascente como a Economia Criativa, que integra diferentes campos de atuação (cultura, tecnologia, moda e design, entre outros), o conceito de território usado (SANTOS, 2002) permite uma compreensão sobre território que rompe com os limites do olhar estritamente econômico ou de rede formal que se possa ter sobre a relação entre esses setores. Sugere-se, desse modo, contemplar na análise de um território as relações sociais e aspectos identitários das pessoas que ocupam determinado espaço, observando os aspectos simbólicos que integram e separam aqueles que habitam, trabalham e visitam um determinado território, considerando-se os elementos históricos, culturais, naturais, políticos e econômicos da sua organização social e material (SANTOS, 2002).

O território usado integra o espaço geográfico e as relações sociais, é o espaço concreto de vida e trabalho humanos. Como campo delimitado de relações sociais, o território usado inscreve a divisão local do trabalho, as relações de cooperação e disputa construídas historicamente, assim como as dimensões política e cultural daquele espaço (SANTOS, 2005), uma vez que as leis da sociedade são históricas, constituídas pelos indivíduos e marcadas pelos seus modos de produção (FARIA, 2011). Esse território constitui um espaço visível nas fábricas, nas lojas, nas instituições, nas moradias e nas pessoas que ocupam uma região e apresentam identidades e história elaboradas conjuntamente ou por divergências.

Essa compreensão permitiria uma nova dimensão aos estudos sobre Economia Criativa, uma vez que o ponto de partida seria a compreensão das particularidades locais, suas forças e contradições. Diferente da abordagem prescritiva presente nos artigos sobre o desenvolvimento de cidades criativas e da proposta de um modelo generalista de análise que parece não se preocupar com a dimensão local que se verifica nos polos criativos, este caminho possibilitaria reconhecer e valorizar as características culturais e criativas de cada território.

No lugar de cidades ou bairros, que seguem uma delimitação política preestabelecida, propõe-se o entendimento de territórios criativos como territórios usados. Assim, concebe-se território criativo como o espaço ocupado por manifestações criativas materiais e simbólicas, que integra pessoas: residentes, comerciantes, produtores, consumidores ou frequentadores que se ligam ao lugar pelas relações sociais e afetivas estabelecidas no decorrer de suas trajetórias de vida. Nesse caso, considera-se para a compreensão desse território: a história das manifestações criativas, como surgem e se alteram ao longo do tempo; a relação estabelecida entre aspectos sociais, culturais, políticos e econômicos no direcionamento das manifestações criativas daquele espaço; a diversidade de bens e serviços criativos apresentadas pelos integrantes do lugar; a relação de continuidades e descontinuidades entre estas formas criativas e os seus contextos nacional e internacional.

Com esta concepção, espera-se poder explorar não apenas as criatividades hegemônicas e reconhecidas no cenário global, valorizando as identidades locais e as formações sociais que marcam cada espaço estudado. Ou seja, dessa forma é possível tanto analisar as redes que se formam em torno de atividades que normalmente não são reconhecidas como conectadas, quanto identificar espaços de disputa e conflito entre aqueles que utilizam o território, ainda que dentro de uma mesma rede ou manifestação criativa. 
Nessa perspectiva, diferentemente da proposta de Lima (2011), é possível explorar as continuidades e descontinuidades de um mesmo território, evitando a tendência de se concentrar a análise em formas de maior poder, concentração ou interesse econômico. Assim, integram-se como elementos centrais o dinamismo e as contradições nas diferentes esferas (econômica, social, cultural, política, técnica, entre outras) que marcam um território.

\section{CONSIDERAÇÕES FINAIS}

O presente trabalho teve como propósito discutir a Economia Criativa com base nos pressupostos epistemológicos e nas concepções de Milton Santos. Para isto, foram exploradas literaturas internacionais e nacionais que abordavam territórios, evidenciadas na discussão de cidades e polos criativos respectivamente. A literatura internacional centra-se nas definições políticas de espaço, além de privilegiar a vertente estrutural-funcionalista e o enfoque econômico para a análise, com o intuito de transformar a Economia Criativa apenas em uma nova área de desenvolvimento econômico. Os trabalhos nacionais, ainda incipientes, têm demonstrado um esforço para incluir elementos simbólicos e culturais na discussão, mas vêm centrando-se na descrição de casos empíricos, carecendo de maior densidade teórica no aprofundamento do debate.

Recorrendo aos aportes teóricos de Milton Santos e assumindo o materialismo histórico como caminho para refletir sobre a Economia Criativa e os conceitos ligados ao espaço, cidades criativas e polos criativos, percebeu-se que esta base teórica vem propondo uma matriz hegemônica de transformação social. É criada uma nova divisão internacional do trabalho na qual aspectos culturais e simbólicos locais passam a ser reorganizados por instituições e empresas com finalidades econômicas - a história é pouco valorizada nesse caso, bem como as manifestações com pouco potencial de serem reconhecidas como "criativas". Assim, ainda que em um esforço inicial, assume-se a pretensão de suprir uma lacuna teórica referente à escassez de delimitações conceituais que contemplem o local e sua articulação com o mundo, concebendo-se uma definição de território criativo que leva em consideração as críticas e limitações ressaltadas por autores referenciados no atual estudo. Diante do exposto, o presente trabalho traz quatro contribuições para a discussão sobre Economia Criativa, elencadas a seguir.

Primeiro, salientar a necessidade de que os estudos nacionais explorem não apenas as criatividades hegemônicas e reconhecidas no cenário global, mas também valorizem as identidades locais e as formações sociais que marcam cada espaço estudado. Assim, seria possível buscar a compreensão da totalidade do espaço, tanto das redes que se formam em torno de atividades que, normalmente, não são reconhecidas como conectadas, quanto de conflitos, disputas e contradições entre aqueles que utilizam um território, ainda que em uma mesma manifestação criativa.

Segundo, a apresentação do conceito de território criativo como o espaço de vida e trabalho humanos, marcado por relações sociais que se constroem em atividades que envolvem a criação, contemplando convergências e divergências construídas historicamente, integrando relações econômicas, culturais e políticas. Dessa forma é possível explorar como os múltiplos elementos que integram determinado espaço se relacionam e se transformam mutuamente, num movimento de transformação ao longo do tempo.

Terceiro, trazer uma perspectiva que permita integrar teoria e prática na produção de conhecimento. O tema cresce em importância no cenário nacional e tem sido foco de políticas públicas para o desenvolvimento regional. No entanto, os espaços criativos têm sido apropriados apenas como delimitações geográficas que precisam ser geridas para apresentar resultados. Este caminho de análise se desconecta da vida material do território, levando à criação de conhecimentos superficiais e potencialmente destruidores das dinâmicas historicamente estabelecidas.

Por fim, a utilização da história como ciência central para compreender a construção e transformação dos territórios criativos. Dessa forma, tempo e espaço formam uma totalidade que permite compreender aspectos gerais e específicos de cada território, as relações e contradições construídas nas atividades criativas e as relações de poder nelas estabelecidas.

Sendo um esforço inicial, são necessários novos trabalhos para ampliar a discussão teórica e empírica sobre Economia Criativa no país. Assim, sugere-se para estudos futuros a análise, em uma perspectiva histórica global, sobre como foram construídas as políticas do Ministério da Cultura para diferentes áreas da economia criativa (arquitetura, design, moda ou jogos eletrônicos, entre outras); e a compreensão das ações de Economia Criativa promovidas por organizações internacionais e seus reflexos no país como forma de expansão de práticas neocolonizantes e de reorganização da divisão internacional do trabalho. 


\section{REFERÊNCIAS}

BENDASOLLI, P. F. et al. Indústrias criativas: definição, limites e possibilidades. Revista de Administração de Empresas, v. 49, n.1, p.10-18, 2009.

BIANCHINI, F.; LANDRY, C. The creative city. London: Demos, 1995.

BORÉN, T.; YOUNG, C. Getting Creative with the 'Creative City'? Towards New Perspectives on Creativity in Urban Policy. International Journal and Regional Research, v. 37, n. 5, p. 1799-1815, 2013.

CHAGAS, E. F. O Método Dialético de Marx: investigação e exposição crítica do objeto. Síntese, v. 38, p. 55- 70, 2011.

CHOI, C. J.; MILLAR, C. C.J.M.; WONG, C. Y. L. Singapore in transition: from technology to culture hub. Journal of Knowledge Management, v. 10, n. 5 , p. 79-91, 2006.

COHENDET, P.; GRANDADAM, D.; SIMON, L. Economics and the ecology of creativity: evidence from the popular music industry. International Review of Applied Economics, v. 23, n. 6, p. 709-722, 2009.

COMUNIAN, R. Rethinking the Creative City: The Role of Complexity, Networks and Interactions in the Urban Creative Economy. Urban Studies, v. 48, n. 6, p. 1157-1179, 2011.

CURRID, E. New York as a Global Creative Hub: a Competitive Analysis of Four Theories on World Cities. Economic Development Quarterly, v. 20, n. 4 , p. $330-350,2006$

DE MARCHI, L. Análise do Plano da Secretaria da Economia Criativa e as transformações na relação entre Estado e cultura no Brasil. Revista Brasileira de Ciência da Comunicação, v. 37, n. 1, 2014.

EVANS, G. Creative Cities, Creative Spaces and Urban Policy. Urban Studies, v. 46, n. 5-6, p. 1003-1040, 2009.

FARIA, J. H. Materialismo Histórico e as Pesquisas em Administração: uma proposição. In: ENCONTRO NACIONAL DOS PROGRAMAS DE PÓS-GRADUAÇÃO E PESQUISAS EM ADMINISTRAÇÃO, 35., 2011, Rio de Janeiro. Anais... Rio de Janeiro: Anpad, 2011. Pp 1-16.

FLORIDA, R. The Economic Geography of Talent. Malden e Oxford: Blackwell Publishing, 2002. Disponível em: <http://www.creativeclass.com/rfcgdb/articles/5\%20The_Economic_Geography_of_Talent. pdf >. Acesso em: 21 set. 2014.

FLORIDA, R. Cities and the Creative Class. New York: City \& Community, 2003.

JAKOB, D. Constructing the creative neighborhood: hopes and limitations of creative city policies in Berlin. City, Culture and Society, v. 1, n. 4, p. 193-198, 2010.

LANDRY, C. The Creativity City Index. City, Culture and Society, v. 2, p. 173-179, 2011

LIMA, S M. S. Polos criativos: um estudo sobre os pequenos territórios criativos brasileiros. Brasília, 2011. Disponível em: <http://www2. cultura.gov.br/economiacriativa/wp-content/uploads/2013/06/ poloscriativos.pdf>. Acesso em: 26 jul. 2013.

LUKÁCS, G. Introdução aos Escritos Estéticos de Marx e Engels. In. MARX, K.; ENGELS, F. Cultura, Arte e Literatura: textos escolhidos. 2. ed. São Paulo: Expressão Popular, 2010.pp. 11-37.

MACHADO, R. M. Da indústria cultural à economia criativa. Revista Alceu, v.9, n.18, p. 83-95, 2009.
MARTINS, R. D.; VAZ, J. C.; CALDAS, E. L. A gestão do desenvolvimento local no Brasil: (des)articulação de atores, instrumentos e território. Revista de Administração Pública, v. 44, n. 3, p. 559-590, 2010.

MINC. Ministério da Cultura do Brasil. Plano da Secretaria da Economia Criativa: políticas, diretrizes e ações - 2011-2014. Brasília: Ministério da Cultura, 2011. Disponível em: < http://www.cultura.gov.br/documents/10913/636523/PLANO+DA+SECRETARIA+DA+ECONOMIA+CRIATI VA/81dd57b6-e43b-43ec-93cf-2a29be1dd071>. Acesso em: 22 out. 2014.

MONTAG, T.; MAERTZ, C. P; BAER, M. A critical analysis of the workplace creativity criterion space. Journal of Management, v. 38, n. 4, p. 1362-1386, 2012.

PARDO, J. Gestão e Governança nas Cidades Criativas. In: KAGEYAMA, Peter; REIS, Ana C. F. (Org.). Cidades Criativas - Perspectivas. São Paulo: Garimpo de Soluções, 2011. p. 84-93.

PAREJA-EASTAWAY, M. Construyendo la Barcelona creative: nuevos actores, nuevas estratégias. Finisterra, v. XLV, n. 90, p. 133-152, 2010.

PRATT, A. C. Creative Cities? Urban Design Journal, v. 106, n. 105, p. 35, 2008.

REIS, A. C. F. Introdução. In: REIS, A. C. F. Economia Criativa como estratégia de desenvolvimento: uma visão dos países em desenvolvimento. São Paulo: Itaú Cultural, 2008.

REIS, A. C. F. Introdução. In: KAGEYAMA, Peter; REIS, Ana C. F. (Org.). Cidades Criativas - Perspectivas. São Paulo: Garimpo de Soluções, 2011.

SANTOS, M. O Brasil: território e sociedade no início do século XXI. Rio de Janeiro: Record, 2002.

SANTOS, M. Sociedade e Espaço: formação social como teoria e como método. In: SANTOS, Milton. Da totalidade ao lugar. São Paulo: Edusp, 2005a.

SANTOS, M. O retorno do território. In: SANTOS, Milton. Da totalidade ao lugar. São Paulo: Edusp, 2005b, pp. 137-144.

SANTOS, M. Sociedade e Espaço: a formação social como teoria e método. In: SANTOS, Milton. Da totalidade ao lugar. São Paulo: Edusp, 2005c.pp. 21-42

SANTOS, M. A natureza do espaço: técnica e tempo, razão e emoção. In: SANTOS, Milton. São Paulo: Edusp, 2006.

SAQUET, M. A. O desenvolvimento numa perspectiva territorial, multidimensional e democrática. Resgate (UNICAMP), v.19, p. 5-15, 2011.

SAQUET, M. A.; SILVA, S. Milton Santos: concepções de geografia, espaço e território. Geo UERJ, v.2, p. 24-42, 2008.

SCOTT, A. J.; STORPER, M. Rethinking human capital, creativity and urban growth. Journal of Economy Geography, v. 9, n. 2, p. 147167,2009

UNCTAD. United Nations Conference on Trade and Development. Creative Economy: A Feasible Development Option. Geneva: UNCTAD, 2010. Disponível em: < http://unctad.org/es/Docs/ditctab20103_ en.pdf >. Acesso em: 22 out. 2014.)

YDE, N. C. De qué está hecha una ciudad creativa. Una propuesta para abordar la cultura, el ócio y la creatividad en la urbe contemporánea. Athenea Digital, v. 12, n. 1, p. 169-190, 2012.

WILLIAMS, R. Cultura e Materialismo. São Paulo: Editora Unesp, 2011. 
Doutora em Administração pela Universidade Federal do Rio Grande do Sul (UFRGS); Professora adjunta na Escola de Administração (EA/UFRGS), Porto Alegre-RS, Brasil. E-mail: lisiane.closs@ufrgs.br

Sidinei Rocha-de-Oliveira

Doutor em Sciences Géstion pela Universitè Pierre Mendès-France em cotutela com Universidade Federal do Rio Grande do Sul (UFRGS); Professor adjunto na Escola de Administração (EA /UFRGS), Porto Alegre - RS, Brasil. E-mail: sroliveira@ea.ufrgs.br 